species of gall midge killing the terminal leaf buds of $S$. viminalis $L$. became very abundant in southern Sweden, and has been ever since. The attack rate of this midge is also considered when breeding material is selected. To further increase the genetic base in the breeding material interspecific crosses are now being made for example between European $S$. viminalis and $S$. schwerinii E. Wolf from the Soviet Union.

\title{
Variability in species of the genus Salix with particular reference to cultivated taxa
}

\section{J. Chmelar̆}

University Botanical Gardens - Arboretum, Brno, Czechoslovakia

The intraspecific variability was studied in the genus Salix. In addition to the observations made in the field and the evaluations of herbarium specimens, the willows growing in the Brno Botanical Garden - Arboretum (affiliated to the Brno College of Agriculture, Czechoslovakia) in particular were studied. Among the several hundred specimens it was possible to detect rigid taxa featuring very low variability, e.g. Salix caesia L., S. myrtilloides L., S. vestita Parsh. on the one hand and species that show an extremely wide variability in certain morphological characteristics on the other, e.g. Salix babylonica L., S. alba L., S. purpurea L.

A survey of the willow cultivars has been completed with emphasis on their individual characteristics, e.g. type of growth, difference in foliage, size of catkins, colouring of twigs, and has detected additional attractive cultivars. There is a possibility in the future to introduce into horticulture a group of new willows suitable for cultivation.

\section{Growth of two arctic/alpine willows, Salix setchelliana (Alaska, U.S.A.) and S. polaris (Kola Peninsula, U.S.S.R.)}

\section{A. Douglas}

Biology Department, Boise State University, Boise, ID. 83725 U.S.A.

Salix setchelliana Ball, a prostrate willow of Alaskan glacial river gravel bars, grows clonally from a peripherally expanding horizontal root-system. To understand the species' success in its temporary habitat, its architectural system was examined during the period 1987-89, and several architectural parameters quantified. This analysis indicated that clones appear to change in time from a 'guerrilla' strategy of environmental exploration to more of a 'battalion' strategy of increased branching of the underground system (Douglas 1991). A similar study of $S$. polaris Wahl., a widely distributed species of tundra habitats, was initiated in 1991. Plants growing in two locations in the Xibini Mountains, U.S.S.R., and in two size categories were excavated and their architectural form described. Data-analysis is in progress. This examination of $S$. polaris will help determine if the temporal changes in growth strategy seen in $S$. setchelliana are typical of low-growing northern willows. 